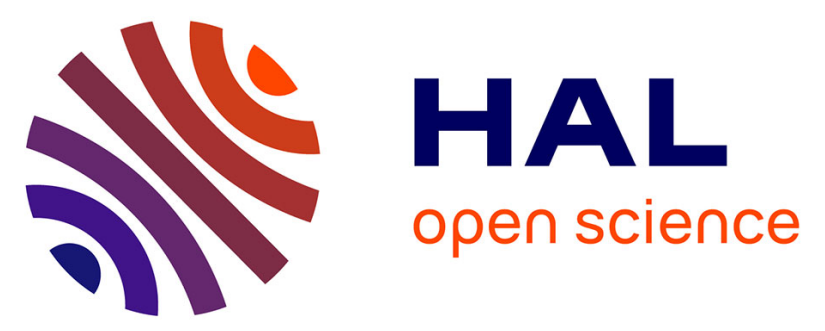

\title{
The Influence of Stroke Location on Cognitive and Mood Impairment. A Voxel-Based Lesion-Symptom Mapping Study
}

Sharmila Sagnier, Fanny Munsch, Antoine Bigourdan, Sabrina Debruxelles, Mathilde Poli, Pauline Renou, Stéphane Olindo, François Rouanet, Vincent Dousset, Thomas Tourdias, et al.

\section{To cite this version:}

Sharmila Sagnier, Fanny Munsch, Antoine Bigourdan, Sabrina Debruxelles, Mathilde Poli, et al.. The Influence of Stroke Location on Cognitive and Mood Impairment. A Voxel-Based LesionSymptom Mapping Study. Journal of Stroke and Cerebrovascular Diseases, 2019, 28, pp.1236 - 1242. 10.1016/j.jstrokecerebrovasdis.2019.01.010 . hal-03486245

\section{HAL Id: hal-03486245 https://hal.science/hal-03486245}

Submitted on 20 Dec 2021

HAL is a multi-disciplinary open access archive for the deposit and dissemination of scientific research documents, whether they are published or not. The documents may come from teaching and research institutions in France or abroad, or from public or private research centers.
L'archive ouverte pluridisciplinaire HAL, est destinée au dépôt et à la diffusion de documents scientifiques de niveau recherche, publiés ou non, émanant des établissements d'enseignement et de recherche français ou étrangers, des laboratoires publics ou privés.

\section{(ㅇ)(1) $\$$}

Distributed under a Creative Commons Attribution - NonCommerciall 4.0 International 


\section{The influence of stroke location on cognitive and mood impairment.}

\section{A voxel-based lesion-symptom mapping study}

Sharmila Sagnier ${ }^{1,2}, \mathrm{MD}$; Fanny Munsch ${ }^{3,4}, \mathrm{PhD}$; Antoine Bigourdan ${ }^{3,4}, \mathrm{MD}$; Sabrina Debruxelles ${ }^{2}$, MD; Mathilde Poli ${ }^{2}, \mathrm{MD}$; Pauline Renou ${ }^{2}, \mathrm{MD}$; Stéphane Olindo ${ }^{2}, \mathrm{MD}$; François Rouanet ${ }^{2}, \mathrm{MD}$; Vincent Dousset ${ }^{3,4}$, MD-PhD; Thomas Tourdias ${ }^{3,4}, \mathrm{MD}-\mathrm{PhD}$; Igor Sibon ${ }^{1,2}, \mathrm{MD}-\mathrm{PhD}$

\section{Institutions:}

${ }^{1}$ UMR-5287 CNRS, Université de Bordeaux, EPHE PSL Research University, 33076 Bordeaux, France

${ }^{2} \mathrm{CHU}$ de Bordeaux, Unité Neuro-vasculaire, 33076 Bordeaux, France

${ }^{3} \mathrm{CHU}$ de Bordeaux, Neuroradiologie, 33076 Bordeaux, France

${ }^{4}$ Neurocentre Magendie INSERM-U1215, Université de Bordeaux, 33076 Bordeaux, France

Words count: 2981

References: 30

Figures: 2

Tables: 2

Key words: Ischemic stroke, cognition, MoCA subscores, mood, brain mapping, magnetic resonance imaging, prospective study

\section{Corresponding author:}

Pr Igor Sibon

Unité Neuro-vasculaire

33076 Bordeaux

France

Mail : igor.sibon@chu-bordeaux.fr

Phone: 33-5-56-79-55-20

Fax: 33-5-56-79-87-02 
Funding: this study was funded by public grants (PHRCI-2012 and ANR-10-LABX-57 from the “TRAIL").

\begin{abstract}
Background and purpose. The role of stroke location as a determinant of mood and cognitive symptoms is still a matter of debate. The aim of this study was to identify the predictive value of ischemic stroke location, on a voxel basis, for mood and cognitive outcome.
\end{abstract}

Materials and methods. A prospective monocentric study including patients with a supratentorial ischemic stroke was conducted. A 3 Tesla brain MRI was performed at baseline. Mood and cognition were assessed using Hospital Anxiety and Depression scale (HAD), Apathy Inventory (AI) and Montreal Cognitive Assessment scale subscores, performed at three months post-stroke. Statistical maps of ischemic stroke location associated with three months mood and cognitive scores were obtained using a voxel-based lesion-symptom mapping (VLSM) approach (Brunner and Munzel test). Significant voxels (FDR corrected-p $<0.01$ ) were identified using the standard MNI152 space template.

Results. Two hundred and sixty-five non-severe stroke patients were included (64\% men, mean age $66 \pm 14$, median National Institute of Health Stroke Score 3, interquartile range 2-6). Ischemic stroke location was not associated with HAD or AI scores. Language, abstraction and delayed recall performances were mainly associated with left-side hemispheric lesions. Lesions in both hemispheres were associated with lower performances in visuospatial and executive functions, naming, attention and orientation.

Conclusion. Ischemic stroke location does not predict mood outcome at three months but is a determinant of cognitive outcome in specific domains. 


$\begin{array}{ll}\text { Abbreviations } \\ \text { VLSM } & \text { Voxel-based lesion-symptom mapping } \\ \text { MoCA } & \text { Montreal Cognitive Assessment } \\ \text { NIHSS } & \text { National Institute of Health Stroke Score } \\ \text { IQCODE } & \text { Informant Questionnaire on Cognitive Decline in the Elderly } \\ \text { HAD-A (-D) } & \text { Hospital Anxiety and Depression-Anxiety (-Depression) } \\ \text { AI } & \text { Apathy Inventory } \\ \text { MNI } & \text { Montreal Neurological Institute } \\ \text { FDR } & \text { False Discovery Rate } \\ \text { SD } & \text { Standard deviation } \\ \text { IQR } & \text { Interquartile range }\end{array}$

\section{Introduction}

Mood disorders and cognitive impairment represent the main clinical expressions of the so-called "invisible" post-stroke handicap. While large infarct volume, widespread leukoaraiosis, or brain atrophy have been associated with their occurrence (1-3), the role of stroke location is still uncertain (3). Indeed, limited date are available about the potential role of precise stroke location, beside the classical associations between aphasia and left side lesions, neglect and right side lesions, visual agnosia and amnesia with posterior lesions (4). This issue can be address by using a voxelbased lesion-symptom mapping (VLSM) approach, a method providing the evaluation of each individual voxel for potential relationship with a given clinical symptom (5). This approach has the advantage to analyse all brain parenchyma on a voxel-by-voxel basis, without grouping patients by lesion site or clinical score cut-off. With this method, the influence of ischemic stroke location on global cognitive functions, assessed by the Montreal Cognitive Assessment (MoCA) scale, has been reported, on top of clinical determinants (6). However, whether stroke location is differentially 
relevant in terms of specific cognitive domain and in terms of mood outcome is still an open question, and heterogeneous results have been published during the last decade (7-10).

The aim of the present study was to apply VLSM analysis to a prospective cohort of ischemic stroke patients, in order to evaluate the predictive value of stroke location for post-stroke anxiety, depression, apathy, and cognitive subdomains assessment measured at three months.

\section{Materials and methods}

\section{Study population}

Data were gathered from the "Brain Before Stroke" study (6), a prospective and monocentric study conducted at the Bordeaux University Hospital. The study was accepted by the regional ethical board (CPP-2012/19 2012-A00190-43) and all patients or their legal representative provided a written informed consent. Inclusion criteria were an age over 18 years old, a diagnosis of supratentorial ischemic stroke confirmed on a brain MRI performed between 24 and 72 hours from symptoms onset (baseline), and a National Institute of Health Stroke Score (NIHSS) comprised between 1 and 25. Patients with pre-stroke history of dementia or psychiatric disorder matching to axis 1 DSM-IV criteria (11), severe post-stroke aphasia impeding mood and cognitive assessment, life threatening disease, MRI contraindication, and non-native French speakers were excluded.

\section{Clinical assessment}

Demographic characteristics, NIHSS and Informant Questionnaire on Cognitive Decline in the Elderly (IQCODE; 12) were recorded at baseline. IQCODE was performed with a relative of the patient, to detect pre-stroke cognitive decline. Mood outcome was evaluated at three months during a medical hospital visit, using patient self-evaluations. The Hospital Anxiety and Depression scale (HAD; 13) included seven questions for the measurement of anxiety on 21 points (HAD-A), and seven other questions for depression on 21 points (HAD-D). The patient version of Apathy 
Inventory (AI; 14) explored the frequency and severity of three dimensions of apathy: emotional blunting (12 points), lack of initiative (12 points), and lack of interest (12 points). Cognitive subdomains were evaluated at three months during the same medical visit, by a trained research assistant blinded to baseline MRI. The MoCA subscores scale (15) were used, exploring visuospatial and executive functions ( 5 points), naming ( 3 points), attention ( 6 points), language ( 3 points), abstraction (2 points), delayed recall (5 points) and orientation (6 points).

\section{Imaging protocol}

A 3 Tesla MRI (General Electrics Medical Systems Discovery MR750W) was performed at baseline. The sequences used for the present study were as follows: diffusion-weighted imaging (DWI) b1000 (echo time [TE] / repetition time [TR] 82.3/9000, field-of-view [FOV] $24 \times 24 \mathrm{~cm}^{2}$, matrix $128 \times 128$, thickness slice $4 \mathrm{~mm}$, gap between slices $0.5 \mathrm{~mm}$ ), and 3D T1 weighted imaging (wi, TE / TR / inversion time [TI] 3.3 / 8.6 / 450, flip angle 12 ${ }^{\circ}$, FOV 24 x $24 \mathrm{~cm}^{2}$, matrix 256 x 256, thickness slice $1 \mathrm{~mm})$.

\section{Imaging processing and statistical analysis}

Ischemic stroke lesions were segmented on DWI, since it has been suggested that baseline DWI correlated well with final infarct volume (16). A semi-automatic segmentation tool available on 3D Slicer 4.3.1 software was used. The mask of each segmented ischemic lesion, which defined ischemic stroke location, was co-registered with DWI and the native 3D T1-wi sequences, before being superimposed on a standard framework, the Montreal Neurological Institute (MNI), using the Statistical Parametric Mapping 8 software available on MATLAB (R2012b). The relationship between ischemic stroke location, mood and cognitive scores was evaluated on a voxel-by-voxel basis by a VLSM approach, using the non-parametric mapping toolbox of MRIcron 4.8.2014 (17). Three months HAD-A, HAD-D, AI and MoCA subscores were analysed in each voxel by the Brunner and Munzel test. Damaged voxels were voxels included in the mask of ischemic stroke 
lesions segmented previously. Significant voxels were damaged voxels wherein scores were significantly lower than in non-damaged voxels. For appropriate use of Brunner and Munzel statistics, only voxels damaged in at least ten subjects were tested (18). The significance threshold was set at 0.01 after multiple comparisons (False Discovery Rate [FDR]). Statistical Z-score maps were generated. An elevated Z-score meant that the ischemic stroke location was significantly and robustly associated with worse performances at three months in the corresponding clinical score. The standard MNI-152 space template was used to identify MNI coordinates of significant clusters of voxels, for at least 50 contiguous voxels.

\section{Results}

Participants and cognitive performances

Two hundred and sixty-five patients displayed complete clinical and imaging evaluations (64\% men, mean age $66 \pm$ SD 14). The flow chart is detailed in Figure 1. Demographic data and results of neuropsychological evaluations at three months are described in Table 1 . The median NIHSS at baseline was 3 (interquartile range [IQR] 2-6). Ischemic stroke lesions involved both right (47\%) and left (47\%) side hemispheres. At three months, median HAD, AI and MoCA scores were respectively 10 (IQR 6-14), 0 (IQR 0-6) and 24 (IQR 21-27).

\section{Relationship between ischemic stroke location and clinical scores}

No significant association was observed between ischemic stroke location and HAD-A, HAD-D and AI. Conversely, several locations of ischemic stroke were associated with MoCA subscores at three months (Figure 2). Only left-side hemispheric lesions were associated with performances in language, abstraction and delayed recall. Performances in visuospatial and executive functions, naming, attention and orientation subdomains were predominantly associated with left-side 
hemispheric lesions, and to a lesser extent with right-side hemispheric lesions. Cerebral gyri associated with MoCA subscores are described in Table 2.

\section{Discussion}

The main result of this study is that, in a population of patients with a recent ischemic supratentorial stroke, ischemic lesion location does not predict the severity of post-stroke affective symptoms while it contributes to predict specific cognitive domains outcome.

The predictive value of stroke location in post-stroke mood disorders has been a debate for many decades $(10,19)$. Some studies suggested a higher risk in patients with lesions involving the left hemisphere (7), the left dorsolateral prefrontal cortex (20), or basal ganglia (21). Our results, using one of the most accurate methodology available to date (VLSM) on a large sample of patients, suggest the absence of relationship between ischemic stroke location and post-stroke affective symptoms. That is in accordance with the results of Gozzi et al. (22), who did not observe any association between damaged voxels and post-stroke depression in a sample of mild ischemic strokes, using statistical parametric mapping. We can hypothesize that, rather than the location, the interruption of brain anatomical or functional networks involved in mood regulation contribute to post-stroke affective disorders (23). Moreover, dysregulation in noradrenalin, dopamine and serotonin neuronal network after stroke might also influence the occurrence of affective and apathetic symptoms, as suggested by Hama et al. (21).

The role of ischemic stroke location on specific cognitive subdomains is in line with the current knowledge on the anatomofunctional role of brain structures in cognitive domains. Our results emphasize the role of fronto-temporo-insular locations, together with deep brain structures, such as the thalamus and basal ganglia $(24,25)$. Unsurprisingly, we observed the main role of left-side hemispheric lesions for most of the cognitive domains, predominantly those in the language field, 
while right-side hemispheric lesions were mainly associated with visuospatial and executive functions (25).

Nevertheless, the results of this study should be interpreted cautiously due to some limits. First, they only apply to patients with minor to moderate ischemic strokes, as represented in our cohort. Obviously, patients with larger ischemic lesions encompassing many cognitive areas will have more diffuse and severe cognitive impairment. Second, the mood scores (HAD and AI) were low in our sample, thus the absence of severe mood impairment might participated to the absence of association between stroke location and mood outcome, albeit we had a large sample of patients. Third, only patients with supratentorial stroke were included, which did not allow us to evaluate the influence of cerebellar lesions on post-stroke cognitive and affective disturbances. Indeed, the role of cerebellum has been suggested through the disruption of cerebello-cerebral connections $(26,27)$. Fourth, cognitive evaluations were limited to the MoCA, which is relatively rough compared to a full battery of neuropsychological tests. Nonetheless, MoCA is a short and well-tolerated test independently associated with post-stroke cognitive impairment $(28,29)$, which can be carried out routinely. In addition, MoCA subdomains have been previously well-associated with more extensive cognitive batteries (30). Fifth, patients with severe aphasia who were not able to achieve the tests were excluded. Neuropsychological assessment adapted to aphasic patients are now available, and such tests should be use in the future, so as not to miss the cognitive outcome of these patients.

\section{Conclusion}

Ischemic stroke location, in minor to moderate strokes, can predict cognitive outcome at three months in various domains, emphasizing the hypothesis of strategic lesion location in post-stroke cognitive outcome. However, ischemic stroke location does not seem to predict affective and apathetic symptoms. 


\section{Compliance with ethical standards}

* Conflict of interest: Sagnier S, Munsch F, Bigourdan A, Debruxelles S, Poli M, Renou P, Olindo S, Rouanet F, Dousset V, Tourdias T and Sibon I declare that they have no conflict of interest.

* Ethical approval: all procedures performed in studies involving human participants were in accordance with the ethical standards of the institutional and regional research committee (CPP2012/19 2012-A00190-43), and with the 1964 Helsinki declaration and its later amendments or comparable ethical standards.

* Informed consent: informed consent was obtained from all individual participants included in the study, or their legal representative.

\section{References}

1. Pendlebury ST, Rothwell PM. Prevalence, incidence, and factors associated with pre-stroke and post-stroke dementia: a systematic review and meta-analysis. Lancet Neurol. 2009;8:1006 18 .

2. Robinson RG, Jorge RE. Post-Stroke Depression: A Review. Am J Psychiatry. 2016;173:221 $\square 31$.

3. Wei N, Yong W, Li X, Zhou Y, Deng M, Zhu H, et al. Post-stroke depression and lesion location: a systematic review. J Neurol. 2015;262:81 $\square 90$.

4. Ferro JM. Hyperacute cognitive stroke syndromes. J Neurol. 2001;248:841 $\square 9$.

5. Bates E, Wilson SM, Saygin AP, Dick F, Sereno MI, Knight RT, et al. Voxel-based lesionsymptom mapping. Nat Neurosci. 2003;6:448 $\square 50$.

6. Munsch F, Sagnier S, Asselineau J, Bigourdan A, Guttmann CR, Debruxelles S, et al. Stroke Location Is an Independent Predictor of Cognitive Outcome. Stroke. 2016;47:66 $\square 73$.

7. Castellanos-Pinedo F, Hernández-Pérez JM, Zurdo M, Rodríguez-Fúnez B, Hernández-Bayo JM, García-Fernández C, et al. Influence of premorbid psychopathology and lesion location on affective and behavioral disorders after ischemic stroke. J Neuropsychiatry Clin Neurosci. 2011;23:340 7 .

8. Nys GMS, van Zandvoort MJE, van der Worp HB, de Haan EHF, de Kort PLM, Kappelle LJ. Early depressive symptoms after stroke: neuropsychological correlates and lesion characteristics. J Neurol Sci. 2005;228:27ロ33. 
9. Chen X, Duan L, Han Y, Tian L, Dai Q, Wang S, et al. Predictors for vascular cognitive impairment in stroke patients. BMC Neurol. 2016;16:115.

10. Nickel A, Thomalla G. Post-Stroke Depression: Impact of Lesion Location and Methodological Limitations-A Topical Review. Front Neurol. 2017;8:498.

11. American Psychiatric Association. Diagnostic and statistical manual of mental disorders (4th ed., text rev.). Washington, DC: Author.

12. Jorm AF. The Informant Questionnaire on cognitive decline in the elderly (IQCODE): a review. Int Psychogeriatr IPA. 2004;16:275 $\square 93$.

13. Zigmond AS, Snaith RP. The hospital anxiety and depression scale. Acta Psychiatr Scand. $1983 ; 67: 361 \square 70$.

14. Robert PH, Clairet S, Benoit M, Koutaich J, Bertogliati C, Tible O, et al. The apathy inventory: assessment of apathy and awareness in Alzheimer's disease, Parkinson's disease and mild cognitive impairment. Int J Geriatr Psychiatry. 2002;17:1099 $\square 105$.

15. Nasreddine ZS, Phillips NA, Bédirian V, Charbonneau S, Whitehead V, Collin I, et al. The Montreal Cognitive Assessment, MoCA: a brief screening tool for mild cognitive impairment. J Am Geriatr Soc. 2005;53:695 $\square 9$.

16. Rivers CS, Wardlaw JM, Armitage PA, Bastin ME, Carpenter TK, Cvoro V, et al. Do Acute Diffusion- and Perfusion-Weighted MRI Lesions Identify Final Infarct Volume in Ischemic Stroke? Stroke. 2006;37:98 $\square 104$.

17. Rorden $\mathrm{C}$, Karnath $\mathrm{H}-\mathrm{O}$, Bonilha L. Improving lesion-symptom mapping. J Cogn Neurosci. 2007;19:1081 $\square 8$.

18. Medina J, Kimberg DY, Chatterjee A, Coslett HB. Inappropriate usage of the Brunner-Munzel test in recent voxel-based lesion-symptom mapping studies. Neuropsychologia. 2010;48:341 $\square$.

19. Carson AJ, MacHale S, Allen K, Lawrie SM, Dennis M, House A, et al. Depression after stroke and lesion location: a systematic review. Lancet. 2000;356(9224):122 $\square 6$.

20. Grajny K, Pyata H, Spiegel K, Lacey EH, Xing S, Brophy C, et al. Depression Symptoms in Chronic Left Hemisphere Stroke Are Related to Dorsolateral Prefrontal Cortex Damage. J Neuropsychiatry Clin Neurosci. 2016;28:292-8.

21. Hama S, Murakami T, Yamashita H, Onoda K, Yamawaki S, Kurisu K. Neuroanatomic pathways associated with monoaminergic dysregulation after stroke. Int J Geriatr Psychiatry. 2017;32:633 $\square 42$.

22. Gozzi SA, Wood AG, Chen J, Vaddadi K, Phan TG. Imaging predictors of poststroke depression: methodological factors in voxel-based analysis. BMJ Open. 2014;4:e004948.

23. Lassalle-Lagadec S, Sibon I, Dilharreguy B, Renou P, Fleury O, Allard M. Subacute default mode network dysfunction in the prediction of post-stroke depression severity. Radiology. 2012;264:218 $\square 24$.

24. Fuster JM. The Prefrontal Cortex-An Update: Time Is of the Essence. Neuron. 2001;30:319 $\square 33$. 
25. Cabeza R, Nyberg L. Imaging cognition II: An empirical review of 275 PET and fMRI studies. J Cogn Neurosci. 2000;12:1 $\square 47$.

26. Baillieux H, De Smet HJ, Dobbeleir A, Paquier PF, De Deyn PP, Mariën P. Cognitive and affective disturbances following focal cerebellar damage in adults: a neuropsychological and SPECT study. Cortex. 2010;46:869 $\square 79$.

27. Kim NY, Lee SC, Shin J-C, Park JE, Kim YW. Voxel-based lesion symptom mapping analysis of depressive mood in patients with isolated cerebellar stroke: A pilot study. NeuroImage Clin. 2017;13:39 $\square 45$.

28. Salvadori E, Pasi M, Poggesi A, Chiti G, Inzitari D, Pantoni L. Predictive value of MoCA in the acute phase of stroke on the diagnosis of mid-term cognitive impairment. $J$ Neurol. 2013;260:2220 $\square 7$.

29. Pendlebury ST, Markwick A, de Jager CA, Zamboni G, Wilcock GK, Rothwell PM. Differences in Cognitive Profile between TIA, Stroke and Elderly Memory Research Subjects: A Comparison of the MMSE and MoCA. Cerebrovasc Dis. 2012;34:48 $\square 54$.

30. Lam B, Middleton LE, Masellis M, Stuss DT, Harry RD, Kiss A, et al. Criterion and convergent validity of the Montreal cognitive assessment with screening and standardized neuropsychological testing. J Am Geriatr Soc. 2013;61:2181 $\square$.

Tables

Table 1. Demographic, clinical and radiological data of all participants

Table 2. Labels of significant clusters of damaged voxels associated with MoCA subscores (> 50 contiguous voxels, $p<0.01$ FDR)

\section{Figure legends}

Figure 1. Patient flow chart

Figure 2. MoCA subscores related to ischemic stroke location (VLSM analysis)

Colour range represents values of Z-scores thresholded for multiple comparisons ( $p<0.01 \mathrm{FDR}$ ).

Voxels in red colour are damaged voxels in which MoCA subscores are the most impaired 
compared with non-damaged voxels. Images are presented in neurological orientation (left is on the left side). 


\section{6: non-inclusion criteria}

- 34 stroke mimics

- 13 infratentorial strokes

- 1 pre-existing cognitive impairment

- 8 MRI contraindication

51: no exploitable MRI

- 28 missing MRI sequences

- 23 images of insufficient quality

56: incomplete clinical assessment at 3 months

- 15 missing data

- 26 lost during follow-up

- 15 deaths before the end of the study 

Table 1. Demographic, clinical and radiological data of all participants

\begin{tabular}{|c|c|}
\hline & $\mathbf{N}=\mathbf{2 6 5}$ \\
\hline \multicolumn{2}{|l|}{ Demographic data } \\
\hline Age, mean (SD) & $66(14)$ \\
\hline Male, n (\%) & $171(64)$ \\
\hline Right-handed, n (\%) & $182(92)$ \\
\hline \multicolumn{2}{|l|}{ Vascular risk factors, $\mathbf{n}(\%)$} \\
\hline Hypertension & $125(47)$ \\
\hline Diabetes mellitus & $45(17)$ \\
\hline Hypercholesterolemia & $106(40)$ \\
\hline Current smoking & $64(24)$ \\
\hline IQCODE at baseline, mean (SD) & $3(0.6)$ \\
\hline NIHSS at baseline, median (IQR) & $3(2-6)$ \\
\hline \multicolumn{2}{|l|}{ Modified Rankin scale at three months, n (\%) } \\
\hline $0,1,2$ & $216(81)$ \\
\hline$\geq 3$ & $51(19)$ \\
\hline Total MoCA/30 at three months, median (IQR) & $24(21-27)$ \\
\hline Visuospatial and executive functions/5 & $4(3-5)$ \\
\hline Naming/3 & $3(3-3)$ \\
\hline Attention/6 & $5(4-6)$ \\
\hline Language/3 & $2(2-3)$ \\
\hline Abstraction $/ 2$ & $2(1-2)$ \\
\hline Delayed recall/5 & $3(2-4)$ \\
\hline Orientation/6 & $6(6-6)$ \\
\hline \multicolumn{2}{|l|}{ HAD at three months, median (IQR) } \\
\hline $\mathrm{HAD}-\mathrm{A} / 21$ & $6(3-8)$ \\
\hline $\mathrm{HAD}-\mathrm{D} / 21$ & $3(1-6)$ \\
\hline $\mathrm{AI} / 36$ at three months, median (IQR) & $0(0-6)$ \\
\hline \multicolumn{2}{|c|}{ Stroke characteristics: hemisphere side and arterial territory, $n(\%)$} \\
\hline Right side & $124(47)$ \\
\hline
\end{tabular}


Left side

Right and left side

Middle cerebral artery

Anterior cerebral artery

Posterior cerebral artery

Anterior choroid artery
$126(47)$

$17(6)$

$202(69)$

$27(9)$

$53(18)$

$11(4)$

$12.1(2.2-36.5)$

Stroke volume $\left(\mathrm{cm}^{3}\right)$, median (IQR)

IQCODE: Informant Questionnaire on Cognitive Decline in the Elderly, NIHSS: National Institute of Health Stroke Score, MoCA: Montreal Cognitive Assessment, HAD-A (-D): Hospital Anxiety and Depression scale-Anxiety (-Depression), AI: Apathy Inventory, SD: standard deviation, IQR: interquartile range 
Table 2. Labels of significant clusters of damaged voxels associated with MoCA subscores ( $>50$ contiguous voxels, $p<0.01$ FDR)

\begin{tabular}{|c|c|c|c|c|c|c|}
\hline \multirow{2}{*}{$\begin{array}{l}\text { MoCA } \\
\text { subscores }\end{array}$} & \multirow[t]{2}{*}{ Cluster labeling } & \multirow{2}{*}{$\begin{array}{c}\text { Maximal } \\
\text { Z-score }\end{array}$} & \multicolumn{3}{|c|}{ MNI coordinates } & \multirow{2}{*}{$\begin{array}{c}\text { Cluster size } \\
\text { (voxels) }\end{array}$} \\
\hline & & & $\mathbf{x}$ & $\mathbf{y}$ & $\mathbf{z}$ & \\
\hline \multirow{4}{*}{$\begin{array}{l}\text { Visuospatial } \\
\text { and executive } \\
\text { functions }\end{array}$} & Left inferior frontal gyrus, pars opercularis & 3.7 & -39 & 8 & 22 & 1782 \\
\hline & Right frontal eye field & 3.5 & 34 & 27 & 39 & 639 \\
\hline & Right supramarginalis gyrus & 3.2 & 50 & -36 & 28 & 184 \\
\hline & Right putamen & 3.2 & 20 & 12 & -12 & 57 \\
\hline \multirow[t]{3}{*}{ Naming } & Left insula & 3.9 & -45 & 2 & -3 & 24931 \\
\hline & Left angular gyrus & 3 & -45 & -60 & 46 & 67 \\
\hline & Right associative visual cortex & 2.7 & 38 & -78 & -16 & 64 \\
\hline \multirow{6}{*}{ Attention } & Left primary motor cortex & 5.3 & -40 & -12 & 15 & 18738 \\
\hline & Left primary somatosensory cortex & 3.6 & -42 & -22 & 36 & 85 \\
\hline & Left anterior prefrontal cortex & 3 & -28 & 45 & -9 & 313 \\
\hline & Right inferior frontal gyrus, pars opercularis & 3 & 33 & 14 & 30 & 174 \\
\hline & Right ventral posterior cingulate cortex & 2.6 & 15 & -52 & 32 & 362 \\
\hline & Right associative visual cortex & 2.6 & 21 & -62 & 20 & 63 \\
\hline \multirow[t]{4}{*}{ Language } & Left primary motor cortex & 6.3 & -50 & -10 & 8 & 27386 \\
\hline & Left angular gyrus & 3.9 & -45 & -69 & 32 & 397 \\
\hline & Left caudate & 3.9 & -10 & -2 & 15 & 122 \\
\hline & Left inferior frontal gyrus, pars orbitalis & 3.6 & -46 & 22 & -15 & 52 \\
\hline \multirow[t]{2}{*}{ Abstraction } & Left inferior frontal gyrus, pars opercularis & 4.9 & -58 & 6 & 12 & 12346 \\
\hline & Left temporopolar area & 3 & -57 & 8 & -16 & 54 \\
\hline \multirow[t]{7}{*}{ Delayed recall } & Left parahippocampal gyrus & 3.9 & -34 & -33 & -20 & 2265 \\
\hline & Left thalamus & 3.9 & -15 & -21 & 0 & 730 \\
\hline & Left associative visual cortex & 3.4 & -8 & -92 & -14 & 471 \\
\hline & Left middle temporal gyrus & 3.4 & -69 & -26 & -4 & 64 \\
\hline & Left dorsolateral prefrontal cortex & 2.9 & -38 & 32 & 22 & 88 \\
\hline & Left temporopolar area & 2.7 & -57 & 8 & -16 & 54 \\
\hline & Left inferior frontal gyrus, pars orbitalis & 2.5 & -39 & 34 & -8 & 59 \\
\hline \multirow[t]{4}{*}{ Orientation } & Right associative visual cortex & 3.1 & 18 & -98 & 4 & 367 \\
\hline & Left parahippocampal gyrus & 3.5 & -24 & -27 & -14 & 85 \\
\hline & Left hippocampus & 2.7 & -24 & -12 & -22 & 100 \\
\hline & Right anterior prefrontal cortex & 2.7 & 27 & 44 & -6 & 54 \\
\hline
\end{tabular}

